\title{
Home-School Relationships: A School Management Perspective
}

\section{Abstract:}

Abu Dhabi, United Arab Emirates (UAE) is in the process of initiating major education reform designed to improve schools. Parental involvement in support of student learning ranks high on the reform agenda. This study explores managerial aspects of implementing homeschool relationships in seven primary Public Private Partnership (PPP) schools in Abu Dhabi, UAE. Participants involved in this study were principals, social workers, teachers, parents and students. Managerial aspects discussed in this paper relate to: a) benefits of home-school relationships; b) roles and responsibilities of stakeholders; c) homeschool communication; and d) constraints and challenges faced in the management of home-school relationships. The findings elicit recommendations for improvement which may inform the work of policymakers, principals, social workers, teachers and parents in their continued efforts to build home-school relationships.

Keywords: Home-school relationships, perceptions of school stakeholders, school change and reforms.

\section{Context of the Study}

The UAE is a federation of seven emirates situated in the southeast of the Arabian Peninsula. Islam is the official religion and Arabic is the official language. It has an infrastructure that is moderating its dependence on oil so education reforms and changes to the schooling system have become a priority for desirable sustainable development. According to his Highness Sheikh Mohammed Bin Zayed Al Nahyan, Crown Prince of Abu Dhabi, the Deputy Supreme Commander of the UAE Armed Forces and the Chairman of Abu Dhabi Educational Council, "the UAE has begun a journey of growth and modernization, as far as reforming the educational system” (ADEC, 2008, p.1).

Reforms in Abu Dhabi are taking place through the Abu Dhabi Education Council (ADEC). ADEC is a non federal government authority established by Sheikh Khalifa in September 2005. ADEC has been allocated the task of developing education and educational institutions 
in the emirates of Abu Dhabi. The council, with the Ministry of Education, is in charge of formulating reform plans within the framework of the UAE's general education policy. ADEC issues licences for educational institutes, supervises education zones and schools and establishes and monitors educational standards in schools. Within the context of reform, ADEC is charged with the task of developing education through curricular, pedagogical and school leadership reforms (Kannan, 2008).

\section{The Context of Educational Reform: Setting the Scene for Home-School Relationships}

In the UAE, the reform agenda for improving schools is strongly voiced by researchers and government officials (Safran, 1997; Davies, 1999). Dr. Al Khaili, the Director General of ADEC, had this to say in critique of the current status of education in Abu Dhabi: “Abu Dhabi hasn’t gone as far as it should in changing the way we teach and what we teach in our classrooms. Teaching is still very traditional with the teachers doing most of the talking and students listening passively. Students are viewed as empty vessels that we must fill with content knowledge. We then expect them to memorize all they've learnt and write it down in exams” (ADEC, 2008, p.1). Dr. Al Khaili states, “we don’t just want to improve our education system, our schools and the performance of our students... we want to be ranked as one of the best education systems in the world" (ibid).

In line with the educational reforms sought in Abu Dhabi, ADEC's Strategic Plan for the 2009-2018 period focuses on six key priorities: 1) elevate school quality in Abu Dhabi to international standards; 2) improve access to P-12 education; 3) provide students with affordable options of high quality private education; 4) preserve UAE culture and heritage and develop successful careers; 5) build ADEC capabilities; and 6) actively engage the stakeholders (ADEC, 2009).

To initiate change in education, the Public Private Partnership ${ }^{1}$ (PPP) initiative was piloted by ADEC in 2006 (ADEC, 2009). The PPP program was launched to improve standards in public schools. PPP schools are synonymously associated with leading change in

\footnotetext{
${ }^{1}$ The Public Private Partnership project launched by ADEC in 2006 was designed to lay foundations for the New School Model introduced in the lower grades and designed to boost education standards. The partnership was established on a three-year contract basis where private operators would help the school achieve standardized goals to improve students performance and align teaching practices to international methods (http://www.thenational.ae/news/uae-news/schools-ppp-future-to-be-revealed-soon)
} 
line with ADEC's reform agenda. According to ADEC statistics for the academic year 20092010, there are 116 PPP schools in Abu Dhabi and this includes the city of Abu Dhabi, the Western region and $\mathrm{Al}$ Ain. Among these 116 schools, 48 are in the city of Abu Dhabi and include 10 secondary schools (three common schools ${ }^{2}$ ), 30 primary schools (three common schools) and the remainder, kindergartens. PPP schools in the UAE are segregated by gender. PPP primary schools for girls are managed by female staff. The majority of PPP male primary schools are managed by male staff. Mixed male-female staffing and administration occurs in a few male primary schools which have western females as PPP supervisors (ADEC, 2010a).

The educational reforms witnessed not only the PPP initiative but, also, the launch of the New School Model in September, 2010. Dr. Pierson, ADEC’s director of P-12 Education, commented that the key elements of the new school model are driven by, "a student centred learning approach, the design of world class facilities based upon the highest international standards, the technology-rich learning environment and a proactive approach that ensures the health, safety and well-being of all students" (www.ameinfo.com/242007). Further, Dr. Al Khaili stated,“the new school model focuses on students' performances and treats them as free thinkers and independent learners via applying the concept of 'whole child philosophy"” (ibid). From September 2010, implementation of the New School Model is expected to involve 171 kindergartens and Cycle 1 schools $^{3}$. The New School Model will be fully implemented across all government schools by the year 2016. Through implementation of the New School Model, ADEC aims to standardize the curriculum, pedagogy and resources across all public schools in Abu Dhabi (ibid).

The New School Model is claimed as, “a new approach to teaching and learning...to improve student learning experiences and to raise academic outcomes of Abu Dhabi students

\footnotetext{
${ }^{2}$ Common Schools: schools that are both primary and secondary and they exist as one school (http://www.dubaifaqs.com/schools-(PPP)-abu-dhabi.ph)

3 Cycle 1 (primary) schools cover kindergarten through to grade five. Secondary schools are broken into two Cycles: Cycle 2 covers grades 6-9 while Cycle 3 covers grades 10-12. (http://www.teachaway.com/teachingpublic-schools-abu-dhabi/abu-dhabi-faq)
} 
to the internationally competitive level” (ADEC, 2010a). The New School Model adopts bilingual teaching (Arabic and English) and the introduction of English as a medium for instruction in Science and Mathematics. The curriculum aims to develop Arabic and English language literacy. As Dr. Al Khaili notes, "a new curriculum, advanced teaching methods and learning materials and resources are introduced in order to enhance student performance by developing the student as a communicator, a thinker and a problem solver, appreciative of the UAE heritage and culture" (www.ameinfo.com/242007).

The inclusion of families, teachers, and community in support of student learning is strongly voiced in the New School Model. The guidelines draw attention to the enhancement of home-school relationships emphasizing “close partnerships between schools and families to improved learning outcomes and ongoing and effective home-school communication" (www.adec.ac/ADECNSMSTRATEGY). The guidelines note that, "when teachers work with families as partners, children's development and progress are maximized” (ibid). Such an emphasis on the role of parents as partners in education can be traced to ADEC's Strategic Plan (2009-2018) priority number six which emphasizes active engagement of stakeholders. As noted in Strategy 6.1, schools must "provide transparent and reliable data (to parents) to decide on their children's education” (ADEC, 2010a, p.24). The call for active engagement of stakeholders is further endorsed by the New School Model Policy 4.4 which emphasizes "parent involvement in children’s education” (ADEC, 2010a, p. 35). Policy 4.4 stipulates that, "Parents play an essential role in their children's education. School staff and parents share responsibility for ensuring that parents are actively involved in their children's education” (ibid). Article 2: P-12 education, Chapter 2.5.5: Learning environment pillar policies states, “The government of Abu Dhabi recognizes that an effective education system requires a strong partnership between parents and schools, and will actively seek to involve parents by keeping them informed of their children's progress, encouraging home support in the learning process and consulting with them on entailed issues...” (ADEC, 2010b, p. 44).

In line with ADEC’s Strategic Plan (2009-2018) and as indicated in Policy 4.4, each school is expected to create an implementation pathway to functionalize home-school relationships (ADEC, 2010a). School stakeholders are required to establish systems, structures and processes that spell out:

- Frequency and content of communication that parents can expect from the school 
- Ways in which the school will communicate children's academic performance inclusive of outlining structures by which students will be assessed

- Opportunities for parents to visit the school and meet with principals, faculty heads, and teachers involved in their children's education

- Opportunities for parents to participate in the school community through structures such as a 'Fathers' or a 'Mothers' council.

In practice, this means that schools are expected to communicate with parents regularly and frequently through a variety of communication strategies - newsletters, telephone calls, SMS, e-mails, letters, internet portals and face-to-face meetings. They are expected to hold one formal parent/teacher meeting per trimester and actively promote parental attendance at these meetings. Schools are expected to provide parents with a handbook detailing the school's education program and all relevant policies that may affect students and their families. In addition to formal communication sent home on a school-wide basis, teachers are invited to contact parents individually to discuss academic and/or behavioral issues that may arise. Similarly, parents are encouraged to keep informed of their children's progress through regular meetings with principals, social workers, faculty heads and teachers. They are encouraged to volunteer and participate in open days, school events, and in 'Fathers' or 'Mothers' councils. Their active involvement includes, but is not limited to:

- Making every effort to ensure that children attend school every day and arrive on time

- Ensuring that children complete their homework assignments

- Frequently asking children about their school day

- Keeping updated with changes at the school (ADEC, 2010a).

\section{Home-School Relationships: An Overview}

The significance, benefits and constraints of home-school relationships and parental involvement are open to controversy. For example, while much research exists in support of home-school relationships, a growing body of research identifies and explains reasons for less involvement on the part of families. Wylie (1999) noted that unemployed and immigrant families facing language and cultural differences were less likely to have contact with teachers and schools. Khan (1996) claims that few opportunities to establish meaningful relationships between the school and parents limits home-school relationships to being, 
"merely ritualistic, rarely providing any real opportunity for substantive negotiation and constructive criticism” (p. 58). Harris and Goodall (2008) note that social and economic factors prevent many parents from fully participating in schooling and schools rather than parents are often 'hard to reach'.

A significant body of literature highlighting features of home-school relationships as making a difference to student learning frequently cite: a focus on promoting academic success (Hill \& Tyson, 2009; Harris \& Goodall, 2008; Fan \& Chan, 2001, Hoover-Dempsey, Battiato, Walker, Reed, DeJong, \& Jones, 2001), creating positive effects on the social development and well being of the child (Fan \& Chan, 2001) and making a positive difference to children's learning and achievement (Harris \& Goodall, 2008). In addition, benefits extend to: integration of families in the social life of the community; democratic parent/school partnerships and practices with school authorities based on increased parental knowledge of how schools operate and an understanding of curricular/pedagogical matters; parents as partners in support of the public face of education; and parental support for government reforms (Hoover-Dempsey, Battiato, Walker, Reed, DeJong, \& Jones, 2001).

Resulting benefits from home-school relationships is not a new concept. Neither is the recognition that home-school relationships are a unitary construct (Epstein, 2001). Epstein (2001), for example, elaborates and delineates home-school relationships into six major categories of parental involvement: parenting (helping families to establish home environments conducive to learning); communicating (designing effective school-home and home-school communications about programs and children's progress); volunteering (recruiting and supporting parent help); learning at home (providing information and ideas to families about how best to help students with homework and other curriculum activities); decision making (parental involvement in school decision making and leadership capacities); and collaborating with community (identifying and integrating resources and services from the community to strengthen school programs, family practices and student learning and development). In a similar vein, Obeidat and Al-Hassan's (2009) study on how twenty-eight teachers in the Hashemite Kingdom of Jordan created parent-community partnerships highlighted the following home-school categories: communicating with parents; involving parents in the learning process; involving the community in the school; pursuing volunteer projects and involving students in the community. Given the categories of home-school relationships and the need to manage family-school interdependency in a variety of ways to 
support student learning, it is little wonder that administrators of schools are asked to develop managerial arrangements that involve parents in a variety of ways. Changes in relationships, attitudes and orientations to home-school relationships necessitates the development and implementation of inclusive school-based policies, supportive committee structures, budget allocations and continuous evaluation of structures, systems and processes.

ADEC’s Strategic Plan (2009-2018) and school reform initiatives emphasize "an active teaching and learning environment supported by families and the community” (ADEC, 2010a, p. 2). The New School Model stresses parents as partners in education. The family and community involvement component of the model calls for close home-school partnerships aimed at improved learning outcomes and ongoing and effective communication between home and school (ADEC, 2010b). Underpinning the reform agenda and in particular the New School Model is an implicit recognition of the positive benefits accrued from parental involvement. Promoting the notion of home-school relationships in Abu Dhabi related to benefiting student learning sits comfortably within the literature citing categories and benefits of parental involvement (see Epstein, 2001; Obeidat \& Al-Hassan, 2009).

\section{Home-School Relationships: Managing Change}

Findings from Khasawneh and Alsagheer's (2007) survey on family involvement in Al-Ain, UAE, not only confirmed the need for increased parent involvement to improve student academic achievement and learning but, also, a model of school and home involvement that facilitates change by attending to: organizational structure, communication systems, programs and planning, family-school forums and monitoring of process. Epstein's (2001) integrated systems theory where the family and school are seen to have overlapping spheres of influence related to learning and child development, suggests schools take the initiative in establishing parent relationships as many parents require guidance on how to help their children at home. To facilitate home-school relationships, Epstein suggests placing the child at the centre of home-school thinking and ensuring school programs and services are family-friendly accounting for the many realities of family life. Home-school relationships, Epstein (2001) suggests must be considered, “a process, not a single event” (p. 420) based on feelings of care involving trust and respect.

Given the educational reforms and changes enhanced by ADEC's Strategic Plan (2009-2018) and the New School Model, there is a need for schools to review their 
infrastructures and managerial capabilities to implement home-school relationships. By way of assistance, ADEC's action plan agenda provided professional development for 325 kindergartens and Cycle 1 public school principals and vice principals in steering their organizations to enact government reform initiatives. These participants were introduced to leadership training, given guidance on development of school strategic plans and community involvement (home-school relationships) within the framework of the New School Model (ADEC, 2008). While such moves are absolutely fundamental to managing change, separating out the implications of this in context demands an understanding of situated complexity and connectivity among stakeholders. For example, pedagogical and curricular changes where English as the medium for delivering the curriculum in core subjects of Science and Mathematics and the presence of English medium teachers (EMTs) from countries such as United States and England teaching students in kindergartens and Cycle 1 public schools continues to impose a level of challenge schools need to address in the area of home-school relationships. In such situations, researchers such as Nunan (2003) and $\mathrm{Hu}$ (2002) caution that implementation of new pedagogies exported across contexts need careful monitoring to prevent failure owing to the mismatch between teachers' methodology and expectations and those of parents.

In the context of Abu Dhabi, the challenges go beyond pedagogy and expectations to difficulties encountered with language factors impeding communication (EMTs inability to talk to Arabic speaking parents and vice versa). Development of home-school relationships in Abu Dhabi schools lends itself to a consideration of context in the design of managerial approaches that bring parents on board and sustain their involvement in schools within a framework of managing change. If the goal is the development of home-school relationships, then communication and shared understandings of what happens in schools needs to align with Policy 4.4 (ADEC, 2010a) and be functionalised through structures, systems and processes. Nevertheless, an inability to implement and embed policy given the realities of practice creates what Honig and Hatch (2004) describe as a policy-reality gap where, as Rae (2005) suggests, "the diversion of the scarce energy of busy people...will only be loosely related to classroom concerns of teachers and students and of their families” (p. 95). As acknowledged by Fullan (1993), policy implementation in practice necessitates working with polar opposites: imposition of change vs. self learning; planning vs. uncertainty; problems vs. 
creative solutions; vision vs. fixed direction; individual vs. group; centralization vs. decentralization and personal vs. systemic changes.

\section{Methodology}

This is an exploratory study which adopts a case study approach .Case study research focused on, "discovery, insight, and understanding from the perspectives of those being studied offers the greatest promise of making significant contributions to the knowledge base and practice of education” (Merriam, 1998 p.1). The study was conducted by three Education Studies faculty members employed at a Higher Education Institution in Abu Dhabi. The researchers were from Australia, New Zealand and the United Kingdom. Their experiences in the education sector of Abu Dhabi spans from three to ten years. One of the three research team members is a fluent speaker and writer of Arabic.

This article explores managerial aspects of implementing home-school relationships in seven PPP schools in Abu Dhabi. The following questions guided the investigation:

- How do systems, structures and processes, inclusive of stakeholders' roles and responsibilities, benefit and facilitate home-school relationships?

- What school managerial reforms are required to enhance home-school relationships within the wider context of Abu Dhabi educational reforms?

\section{Research Design}

This study took place during the academic year 2010-2011. It was conducted in 7 Abu Dhabi PPP Cycle 1 schools (4 female schools and 3 male schools). Two schools from the sample were categorized as inner city and the remaining five as suburban. Six of the selected PPP schools were managed by female staff and one male school had male staff. All schools had female PPP supervisors.

Participants invited to take part in the study included: 7 principals, 7 social workers, 1 teacher per year level from each school (in total 5 grade levels and 35 teacher participants), 1 student per grade level (in total 5 grades and 35 student participants) and 1 parent per year level from each school (as per above, a total of 35 parents). Table 1 provides a breakdown of participant details with reference to ethnicity and gender details. 
Table 1: Participants ethnicity and gender details

*Female (F) Male (M)

\begin{tabular}{|c|c|c|c|c|c|c|c|}
\hline & $\begin{array}{l}\text { School } 1 \\
\text { Female }\end{array}$ & $\begin{array}{l}\text { School } 2 \\
\text { Female }\end{array}$ & $\begin{array}{l}\text { School } 3 \\
\text { Male }\end{array}$ & $\begin{array}{l}\text { School } 4 \\
\text { Male }\end{array}$ & $\begin{array}{l}\text { School } 5 \\
\text { Female }\end{array}$ & $\begin{array}{l}\text { School } 6 \\
\text { Female }\end{array}$ & $\begin{array}{l}\text { School } 7 \\
\text { Male }\end{array}$ \\
\hline Principal & $\begin{array}{l}\text { F } \\
\text { Emirati }\end{array}$ & $\begin{array}{l}\mathrm{F} \\
\text { Emirati }\end{array}$ & $\begin{array}{l}\mathrm{M} \\
\text { Emirati }\end{array}$ & $\begin{array}{l}\text { F } \\
\text { Emirati }\end{array}$ & $\begin{array}{l}\text { F } \\
\text { Emirati }\end{array}$ & $\begin{array}{l}\mathrm{F} \\
\text { Emirati }\end{array}$ & $\begin{array}{l}\text { F } \\
\text { Emirati }\end{array}$ \\
\hline $\begin{array}{l}\text { Social } \\
\text { Worker }\end{array}$ & $\begin{array}{l}\text { F } \\
\text { Emirati }\end{array}$ & $\begin{array}{l}\mathrm{F} \\
\text { Emirati }\end{array}$ & $\begin{array}{l}\mathrm{M} \\
\text { Emirati }\end{array}$ & $\begin{array}{l}\text { F } \\
\text { Emirati }\end{array}$ & $\begin{array}{l}\text { F } \\
\text { Emirati }\end{array}$ & $\begin{array}{l}\mathrm{F} \\
\text { Emirati }\end{array}$ & $\begin{array}{l}\text { F } \\
\text { Emirati }\end{array}$ \\
\hline Teachers & $\begin{array}{l}\text { F } \\
\text { 3Emirati } \\
\text { 1Arab } \\
\text { non } \\
\text { Emirati } \\
\text { 1Western }\end{array}$ & $\begin{array}{l}\mathrm{F} \\
\text { 5Emirati }\end{array}$ & $\begin{array}{l}\text { M } \\
\text { 4Emirati } \\
\text { 1Western }\end{array}$ & $\begin{array}{l}\text { F } \\
\text { 2Emirati } \\
\text { 3Arab } \\
\text { non } \\
\text { Emirati }\end{array}$ & $\begin{array}{l}\mathrm{F} \\
\text { 5Emirati }\end{array}$ & $\begin{array}{l}\text { F } \\
\text { 3Emirati } \\
\text { 1Arab } \\
\text { non } \\
\text { Emirati } \\
\text { 1Western }\end{array}$ & $\begin{array}{l}\mathrm{F} \\
\text { 5Emirati }\end{array}$ \\
\hline Students & $\begin{array}{l}\text { F } \\
\text { Emirati }\end{array}$ & $\begin{array}{l}\text { F } \\
\text { Emirati }\end{array}$ & $\begin{array}{l}\mathrm{M} \\
\text { Emirati }\end{array}$ & $\begin{array}{l}\text { M } \\
\text { Emirati }\end{array}$ & $\begin{array}{l}\text { F } \\
\text { Emirati }\end{array}$ & $\begin{array}{l}\mathrm{F} \\
\text { Emirati }\end{array}$ & $\begin{array}{l}\text { M } \\
\text { Emirati }\end{array}$ \\
\hline Parents & $\begin{array}{l}\text { F } \\
\text { 2Arab } \\
\text { non } \\
\text { Emirati }\end{array}$ & $\begin{array}{l}\text { F } \\
\text { All } \\
\text { Emirati }\end{array}$ & $\begin{array}{l}4 \mathrm{M} 1 \mathrm{~F} \\
\text { 1Arab } \\
\text { non } \\
\text { Emirati }\end{array}$ & $\begin{array}{l}\text { F } \\
\text { 3Arab } \\
\text { non } \\
\text { Emirati } \\
\end{array}$ & $\begin{array}{l}\text { F } \\
\text { All } \\
\text { Emirati }\end{array}$ & $\begin{array}{l}\text { F } \\
\text { All } \\
\text { Emirati }\end{array}$ & $\begin{array}{l}\text { F } \\
1 \text { Arab } \\
\text { non } \\
\text { Emirati }\end{array}$ \\
\hline
\end{tabular}

The participants were selected by purposive sampling. As Patton (1990) explains, "the logic and power of purposive sampling lies in selecting information-rich cases for study" (p. 169, italics in the original). Parent participants were selected for their involvement in the school for at least a year, and for their involvement in a mothers' council or other schoolbased activities. Parents were Arabic native speakers, predominantly Emiratis. Arab, nonEmirati mothers traced their ethnicity to Arab countries other than the UAE such as Sudan, Somalia, Syria, Jordan and Palestine. Students invited to take part in this study had to be able to express an opinion on the topic of home-school relationships. Teachers who had been employed in the school for at least a year and involved with parents in a range of schoolbased activities were invited to participate in the study. Emirati, expatriate teachers (nonArabs), and expatriate English medium teachers (EMTs) from the West participated in this study. EMT teachers teach English and Science and Mathematics in English. Teachers of Arabic, Islamic Studies and Social Studies are native Arabic speakers (Emirati and non- 
Emirati Arabs). Students have the same contact hours with EMT and Arabic speaking teachers. Principals and social workers were all Emiratis and were automatically invited to participate in the study.

The criteria for selection of teachers, parents and students were communicated to principals and social workers of respective schools. In consultation with these school authorities, decisions regarding the selection of teachers, parents and students were taken. Participants were informed of the study via bilingual introductory letters. Bilingual consent forms were attached to the letters and given to school authorities to distribute to teachers and parents including those whose children had been identified as taking part in the study. Signed consent forms were handed back to school authorities and this indicated a willingness to participate in the study. All written and verbal communication to participants occurred in English or Arabic. Confirmation of consent was also orally obtained as part of the protocol that preceded each interview. Parents were re-informed about the purpose of the study and confidentiality measures and rights to withdraw should they so wish.

Forty nine individual semi-structured interviews were conducted with principals, social workers and teachers and seven focus group interviews were held separately with parents and students. All interviews took place at the schools. The semi-structured individual interviews were forty minutes in duration and the focus groups lasted an hour.

Semi-structured interviews allowed the researchers to enter the inner world of another person to gain understanding from their perspective (Patton, 1990). Interviews afforded depth of data (Denzin \& Lincoln, 2003) because participants were encouraged to reflect, discuss and share their thoughts, beliefs and experiences. In keeping with participants' wishes and respect for cultural protocols, the decision was made not to audio-tape the interviews but to manually record participants' responses at the time of the interview. To obtain rich data and verify the authenticity of data collected, the following measures were undertaken:

- The bilingual interview guide was given to participants prior to interview commencement with reminders that questions were designed to facilitate conversation. 
- Participants were given time to read through the questions and encouraged to make notes, seek clarification and confirm confidentiality measures for themselves and the institutions they represented.

- All interviews involved at least two members of the research team.

- At all interviews, either the research team member fluent in speaking and writing Arabic was present and, on the rare occasion when this was not possible, the services of an Arabic/English translator was secured to facilitate the conversation. In the case of the latter, the translator was asked to sign a confidentiality agreement, made familiar with the nature of the interview, taken through the interview process and instructed to provide verbatim translations of participants' responses from Arabic to English. Such steps paved the way for cross-reversible translation to verify data accuracy.

- During the interview, participants who chose to communicate in Arabic had their responses translated into English. Principals and parents chose to communicate in Arabic only. The social workers, teachers and students communicated in either English or Arabic. Research team members who spoke English were able to probe and ask further questions through the translator.

- Responses were recorded manually by the interviewers conducting the study. The member of the research team fluent in speaking and writing Arabic recorded responses in Arabic as per need. These responses were later translated into English. English speaking researchers recorded participants’ responses in English.

- This process of communication, albeit time consuming, facilitated the elicitation of deeper information and verification of information given by participants.

Focus groups were considered the most realistic method of data collection for parents and students given time constraints. Focus groups were structured along similar lines to that of the semi-structured interviews: the interview guide served to facilitate conversations; the Arabic speaking member of the research team or a translator helped facilitate the interviews; and protocols and recording of information were similar to that initiated at the semistructured interviews. Focus groups triggered interaction and dialogue among the participants (Morgan, 1997). They allowed similarities and differences in terms of opinions and 
experiences to surface and this gave the data its richness and multi-dimensional quality. In the findings, excerpts recalling parents' and students' voices are collectively acknowledged as 'parents' and 'students' from respective schools.

The interview guide used to steer the conversation contained questions that ascertained perceptions of key aspects of home-school relationships as expressed by various stakeholders. The focus remained on defining parental involvement, determining types of involvement, detailing purposes and systems of communication, and ascertaining constraints, limitations and thoughts on future improvements. Examples of questions are as follows:

- What does parental involvement mean to you? Please explain.

- How does the school communicate to inform you about ways to get involved?

- Does the school have any policies to encourage or enhance parental involvement? What are these policies?

- Are there any factors that may prevent or restrict you from being involved at your child's school?

In terms of data analysis, the researchers began with an initial reading of one interview transcript. Every unit of interview data was coded and grouped into tentative categories and subcategories using the following process. For example, an initial transcript was read to ascertain data that appeared significant to home-school relationships. A second reading of the same transcript prompted the underlining of key phrases, words or sentences that had deliberate bearing on the topic. Continuous questioning in the form of, "What does this mean?” initiated additional thoughts and ideas around the topic. Summary notes were made in the margin of the transcript. These notations formed preliminary codes. The process was applied to other interview transcripts with the idea of determining similarities and differences. This first level data analysis produced initial codes that established tentative categories and properties. Once all the interview data was coded, a second layer of analysis was conducted to determine patterns related to management practices. What followed, once again, involved sorting and deciding which data, categories and sub-categories were established and which required moving and reconstructing as new perceptions, insights and understandings emerged. As the analysis proceeded, an analytical framework was developed. The framework, sequentially and cumulatively developed, captured the nature of managerial 
practices related to home-school relationships. Inter-coder reliability was achieved by all researchers working with the data in the data analysis/interpretation process.

\section{Limitations}

A limitation of the study was the lack of dedicated time and human resources. This impacted on number and type of schools selected. The Western and Al-Ain regions were excluded from the study as were kindergartens and secondary schools. Although the criteria for selection of teachers, parents and students was determined by the researchers and clearly communicated to principals and social workers, final participant selection was authorized by school authorities. This potential for bias was, therefore, unavoidable within the context. Mothers were the majority of parents interviewed as they had (apart from one male school) the greatest presence. Fathers were either under represented, did not meet the criteria for selection or were unavailable. An imbalance in parent voice is, therefore, acknowledged.

\section{Findings}

The findings presented relate to the management of home-school relationships. Data presented focuses on: benefits of home-school relationships; roles and responsibilities of stakeholders; home-school communication; and constraints and challenges.

\section{Benefits of Home-School Relationships}

As voiced by stakeholders, the metaphors that capture the nature of home-school relationships include: "the family and school should have two hands clapping together" (Parents 5) and "home-school relationships mean two channel systems of communication" (Social worker 5). These metaphors indicate a valuing of parental involvement. Findings presented in this section emphasize the benefits of home-school relationships in terms of learning, catering for the child's well being and managing change.

\section{Benefits Connected with Learning}

Statements by stakeholders reinforce the connection between home and school in support of student learning. They confirm: placement of the child at the centre of homeschool thinking; the school creating opportunities for home-school sharing of information related to learning; and provision of learning opportunities for parents to increase their knowledge on curriculum and pedagogical matters: 


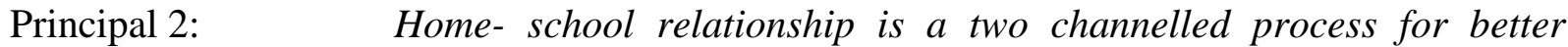
learning.

Principal 5: $\quad$ Parental involvement is better for getting to know about teaching strategies and how the teacher manages the class.

Social worker 2: $\quad$ It is an inseparable part of the education system.

Social worker 3: $\quad$ Parents have to prepare their students for the learning process by encouraging them to go to school and supporting them at home in the learning process.

Teacher 2: $\quad$ School and home is one organisation and the product will be good learning for students.

Teacher 6: $\quad$ I want them (parents) to share in activities such as games day. I want them to be in the classrooms. I want them to sit with the teacher when I am assessing. And I want them to be involved in remedial lessons.

Parents 3: $\quad$ Parents need a clear idea about the curriculum, teaching methods, education and behaviour. Home-school relationships are important in supporting children at home.

Students 6: $\quad$ We learn the words and what they mean in English because the school sends a letter about it so our parents can help us prepare at home.

\section{Benefits Connected with the Child's Well Being}

Apart from support given to learning, home-school relationships are valued for the opportunities they create to enhance the well being of children:

Principal 4:

Principal 2:

Social worker 1:

Teacher 2:

Teacher 5:

Parents 1:

Students 6:
Parent involvement makes the student happier at school.

The impact is psychological because an involved mum makes the daughter happier and gives her a pride to see her mum in the school. Parents should be close to know everything about the child.

We have had cases of theft where the girls are stealing so have to invite the mums to discuss the problem with her and see if the student is deprived. Parental involvement improves behaviour problems. Bullying is minimised through parental involvement.

If the parents are involved they can help a lot. Involvement assists in improving behaviour and psychological dispositions.

The teacher is a second mother to the student when they all discuss the problem with the child.

My parents bring little gifts for all students who have improved. This makes us all feel happy.

\section{Managing Change}

The following statement by one principal succinctly captures the complexities facing schools in the current context of reform and change, "we are living in two separate worlds. There is a gap between the school and the home. There are new trends in education and the parents are unaware of these changes...The parents are not accepting of the curricular 
instructional material changes. The discipline at home is a contradiction with what we try to reinforce at school...The student is living in two contradictory worlds” (Principal 4).

Data from this study reveal that the benefits of initiating and managing home-school relationships extend to building parents' knowledge about the reforms and developing their understanding of curricular and pedagogical change. The inference is that increasing parents' knowledge on the new methodologies enhances their ability to support their children's learning at home. Data indicates that shifts in stakeholders' attitudes, behaviours and a willingness to adjust systems, structures and processes promotes a mindset that values homeschool relationships and this acts to springboard change:

Principal 6: $\quad$ I invite teachers to plan curriculum workshops and English courses for parents....My plan is to make training for some parents and for students who have behavioural problems...I created the student-teacher advising program.

Principal 2: $\quad$ There is a suggestion box that we leave at the reception...we take feedback from parents to improve and this encourages parents to become involved.

Social Worker 1: $\quad$ One of the ideas to accommodate change is having an open day - a BBQ fun day. Open days build strong relationships with parents.

Teacher 4: $\quad$ Due to curricular changes, the school organizes meeting once a month and parents are invited to attend and check on their children's progress.

Parents 7: $\quad$ Sometimes two out of five messages in the school's vision and mission are in support of parental involvement.

\section{Roles and Responsibilities of Stakeholders}

Data on roles and responsibilities of stakeholders are presented from the viewpoint of each stakeholder groups' perception of their involvement in managing home-school relationships. Stakeholders perceive their roles and responsibilities as connected to learning, contributing to the social aspect of school functioning, engagement in home-school communication, and participating in guidance and counselling. The data presented is sectionalized to capture the voices of principals, social workers, teachers, and parents separately. Students confirm the claims made by stakeholders of what is perceived to be their roles and responsibilities.

\section{Principals}

Principals considered themselves proponents of home-school relationships because:

Principal 6: $\quad$ We are the link between ADEC and parents. 
Principal 3: $\quad$ We are a link between the parents and the teachers. It is very important for parents to know the teachers, the services in the school and be aware of his child's result.

Principals act as advisors to parents:

Principal 6: $\quad$ I advise the parent on what is good for the student. I have a plan for each student.

Principal 7: $\quad$ I am the second mother here in the school.

In managerial capacities, principals initiate home-school relationships as it is a "major factor in achieving school improvement” (Principal 7). In this regard, they engage in strategic planning and establish systems, structures and processes in support:

Principal 2: $\quad$ We have put an annual program to improve parental involvement. Principal 5: $\quad$ I arrange parent meetings...open days and communicate with parents.

Principal 2: $\quad$ We already introduced new changes from five to seven in the evenings and this makes dads take part.

Principals elicit the contributions of others in managing home-school relationships:

Principal 7: $\quad$ My plan is to make training for some parents. I invite teachers to take workshops and English course.

Principal 2: We need a 'Mothers' council even though this is a boys' school. Breaking the ice with home means more women will encourage mums to come.

Principal 7: $\quad$ Parents need to be involved and when parents are not involved I ask the teachers to help the students.

\section{Social Workers}

Social workers perceive themselves to be at the hub of all home-school contact. They described their roles and responsibilities as multifaceted. Given the reform agenda, they view their role as advising parents on matters of educational and behavioural concerns, building home-school bonds, organizing parent workshops on curricular, pedagogical, and instructional change and promoting home-school relationships through facilitating opportunities for dialogue:

Social Worker 2: I tell parents what happens in the school...give advice - teach good behaviour ...run workshops for parents...and build relationships between the parents and the school to help children achieve their goals... and feel better about their parents helping and monitoring them at home.

Social Worker 3: I prepare an educational environment to meet the goals of ADEC and make parents aware of how to solve the education problems, take their ideas and opinions about the learning activities that best suit the child and encourage participation. 
Social Worker 5: I create two channel communication systems where parents know what the gap is at school and the school knows what the gap is at home.

\section{Teachers}

Teachers stated that their roles and responsibilities involve communicating with parents on matters of curriculum and learning. The teachers from one school indicated that their involvement with parents was also in the design of individual education plans for special needs students. Data indicates that some teachers were uncertain about initiating contact with parents for personal reasons, "I send, at the beginning of the year, a message with the curriculum that they will learn and send my phone number. Not all the teachers do this. For me it is important” (Teacher 4). Teachers supported their school's stance in building homeschool relationships. They also noted that parent apathy to get involved negatively impacted the on-going development and sustainment of home-school relationships:

Teacher 2:

Now we (the school) don't have text books so we show the parents what the children are learning. Parents are used to having books but now they have worksheets and experiments. Parents complain before why no books? What are they learning? We don't know how to teach them at home? In workshops we explain to them and we give them experiments and let them try and they get the new ideas. We send them weekly plans for each grade and tell them what we are going to study. It is a way of communication so they have an idea of what the children will study.

Teacher 5: $\quad$ We have parent teacher conferences on an individual basis.

\section{Parents}

Data from principals and teachers acknowledge that parents support the school:

Principal 5: $\quad$ Parental participation occurs in advisory counselling, workshops and extracurricular activities; delivering awareness campaigns about safety on the bus, cleanliness, hygiene and good conduct; preparing handouts; volunteering to help teachers in events such as National day; and contributing in events like National day, Math days and sport events.

Teacher 3: $\quad$ Parents take part in decorating the school and contributing to the library and this assists the school.

Parents note their roles and responsibilities as encompassing the following: involvement in matters of academic and behavioural concerns related to their child; support given in organizing social events; volunteering; and building the knowledge base of other parents in the community by disseminating information on education and social matters: 
Parents 4:

Parents 5:

Parents 6:

Parents 7:
We help the school by taking part in social celebrations

We build better teacher child relationships and teach other parents how to teach and raise their children.

We boost the self-esteem of children by taking part in educational activities.

We help the teachers by supporting learning at home.

\section{Students}

Students' commented that their parents' roles and responsibilities were mainly in support of their learning. They linked this support to assistance given in completion of homework and participation in extracurricular activities. Home-school relationships were conceived as teachers and parents communicating on matters of academic and behavioural concerns. School structures that facilitated this were parent/teacher interviews, meetings, social events, mothers' involvement in the 'Mothers' council and home-school correspondence through newsletters, SMS messages and letters. Students confirmed that their school was informing parents of the New School Model through workshops and lectures:

Students 2: $\quad$ We go to trips. My parents come to help

Students 4: $\quad$ They (parents) come for celebrations

Students 5: $\quad$ The school organises lectures about child development for mums.

Students 6: $\quad$ Our mums help in photocopying and activities for celebrations.

Students 7: $\quad$ They help in cleanliness, hygiene and nutrition campaigns.

\section{Home-School Communication}

Systems, structures and processes of communication are designed to disseminate information, create home-school links and provide opportunities for dialogue. Findings presented in this section explain pathways for communication and systems, structures and processes involved.

\section{Pathways of Communication}

Home to school and school to home communication was found to be layered spanning the different organizational layers. Data collected and analysed suggested a communication continuum extending from one-way school to home information giving to parents, to twoway school to home and home to school dialogue and a three-way process of staff, parents and student involvement on matters of education/behaviour concern. 
One-way, school to home communication disseminates general information to parents on matters of education and school events:

Social Worker 3: $\quad$ We prepare an educational environment to meet the goals set by $A D E C$. We tell the parents what their kids are studying and give them a clear idea of the curriculum and the importance of their role in the school process.

Parents 1: $\quad$ Letters are sent home when the school needs anything or when there is a special occasion like an open day.

Students 1: $\quad$ The school sends a letter about what we learn like a test and our new dictation words.

Two-way, school to home and home to school communication encourages the giving and sharing of information that is child centred related to academic and/or behaviour needs:

Principal 4: $\quad$ Communication is purposeful...inviting them specially ...and when the purpose concerns academic and disciplinary problems.

Principal 6: $\quad$ We call parents of weak students to come and meet with us. This builds strong bonds between the teacher and the student.

Parents 6: $\quad$ Two channel system of communication gets parents involved in the methodology of teaching and knowing about their children's levels and grades.

Students 6: $\quad$ Parents participate in graduation ceremonies and prize giving.

Three-way, school to home and home to school communication involves the school, parents and students in decision making and planning to address individual needs:

Principal 7: $\quad$ I have a plan for each student. I invite parents to meet with me on a case basis. All interviews are documented. When parents explain and teachers discuss issues I would know what's missing. I want to do this individual parents/teachers meeting to discuss cases one by one.

Social Worker 3: $\quad$ Parents and students take part in education.

Teacher 7: $\quad$ Each teacher this year they started this project for all grades and each teacher is allocated one student to follow up for his behaviour and academic need. This is a pilot study. The teacher acts as a mother for the allocated student and so many students benefitted and improved.

Parents 1: $\quad$ The teacher is a mother to the student when discussing the problem with the child.

\section{Systems, Structures and Processes}

Various systems, structures and processes facilitate home-school communication. These include: the social worker acting in a home-school liaison capacity, parent participation in the 'Mothers' council, written dissemination of information, reporting back on student data at 
scheduled parent/teacher meetings, and workshops for parents on curriculum and pedagogical changes linked to the New School Model. Details on each are provided below.

- The role of the social worker is crucial in the transference and dissemination of information. Social workers are responsible for engineering opportunities for direct contact between the teachers and parents and providing both parties with information that addresses the academic and behavioural concerns of the child. As voiced by one principal, "the parents are welcome to arrange times to meet with teachers through the two social workers" (Principal 1). Social workers confirm, "if the teacher has a need, the social worker calls the parent to come...In addition, the social worker prepares Individual Education Plans” (Social Worker 1). In addition, social workers facilitate the giving of generic school information and enlist the help of parents in school-based activities and social events: "some parents they come and have an idea to help (so) they come and talk to the social worker” (Social Worker 2). Social workers facilitate parent workshops on curriculum and pedagogy: "we run workshops, build relationships between the parents and the school” (Social Worker 2).

- Schools communicate with parents through the "Mothers' Council” (Teacher 5). The "Mothers' Council” exists as a platform for: mothers to "communicate with the administration" (Parents 5); make suggestions, "so the school knows what the kids needs and the parents know what the kids needs” (Parents 2); bring parents on board by, "giving invitations to attend workshops" (Parents 5); "selling things (to benefit the school); organizing lectures for other mums on child development; and doing activities for kids like awarding prizes and organizing competitions” (Students 2).

- Written dissemination of information on educational matters occurs through: class or school newsletters sent home on a weekly or monthly basis, "when we have a test and new unit dictation words...the school send a letter about it” (Students 1); letters, "sent home when the school needs anything or when there is a special occasion like open day” (Parents 1); school magazines and brochures; and SMS messages.

- Schools report back assessment data at scheduled parent/teacher meetings as stipulated by ADEC. A principal stated: "we arrange parent meetings, open days to communicate with parents” (Principal 5). Teachers claim, "we have parent/teacher conferences on an individual basis" (Teacher 2) and "the school organizes meetings 
once a month and parents are invited to attend and check on their children's progress” (Teacher 4). Parents confirm, "the school invites us to attend parent-teacher meetings to check on achievement” (Parents 5). Despite this, some parents claim the practice is not consistently applied, "not in all subjects and not in all grades” (Parents 7).

- Evidence suggests that schools organise workshops for parents where curricular and pedagogical changes as inherent in the New School Model are explained. Comments in support include: “we have put an annual program to improve parents’ knowledge. We run workshops for this" (Principal 6); "we give them a clear idea of the curriculum through meetings and make them aware of how to deal and solve education problems" (Social Worker 3): "last year we had a class for parents on computers. Parents don't know the basics. After that parents said they wanted more courses. The workshops are very important for parents because now they understand what the children are doing" (Teacher 7); and "the school gives us a clear idea about the curriculum through workshops” (Parents 3).

\section{Constraints and Challenges in the Management of Home-school Relationships}

This section presents evidence on the following constraints and challenges faced in the management of home-school relationships in schools. They revolve around: challenges of context; implementation of policy; budgeting restrictions; misconceptions of roles and responsibilities; factors impinging communication and managerial adjustments to enhance home-school relationships.

\section{Challenges of Context}

Curricular and pedagogical changes and parental involvement are aspects of the reform said to improve schools and bolster student learning. Successful implementation of these is acknowledged by stakeholders as not only their responsibility but, also, that of ADEC. The rapidity within which these changes have been introduced and their implementation expected has been a source of challenge. The following statements capture the nature of these challenges as they appear relevant to the management of home-school relationships in areas related to curriculum and communication between the EMTs and parents. They portray the complexity of factors and competing agendas which affect the management of home-school relationships on three levels: 1) the management changes at the 
school operation level where the communication pathways shifted from the centralised authority (Ministry of Education - ADEZ) to the decentralised authority (ADEC) 2), curricular changes traced to the introduction of EMTs and the teaching of Math and Science in English and 3) parental involvement within a complex socio-cultural milieu:

Related to shifts in communication pathways, the following comments were made:

Principal 2: $\quad A D E Z$ is closed now because of the integration between ADEC and ADEZ...ADEC has organized SMS but it is still not in use. The voice of the principal is not listened to; most policies apply to all schools but there is no testing or piloting.

Social Worker 4: $\quad$ ADEC promised to functionalize the SMS service so we can communicate with parents. Not functionalizing the SMS service means no communication with parents.

Parents 2: $\quad$ The email has not been functionalized due to administrative changes at the macro level.

Related to curricular changes, the following comments were made:

Principal 3: $\quad$ ADEC doesn't consider the parents view of the curriculum change. There are no parent representatives at ADEC when it comes to the curriculum. ADEC needs to listen through representatives.

Social Worker 1: $\quad$ ADEC has changed curriculum and pedagogy and made everything in English: Maths in English, Science in English. Now in English it is very difficult especially since we have foreign teachers. We do not have a text book.

Teachers 3: $\quad$ Parents always complain about the new curriculum and that they don't understand it.

Parents 3: According to ADEC, we have continuous assessment so the father came to school once to collect the report and the father thought everything was OK...the administration should tell the parents that the policy of continuous assessment asks for different things from parents.

Students 1: $\quad$ My mother doesn't know anything about the project of the new curriculum.

Socio-cultural factors that are linked to societal norms and the segregated school system deter parents from getting involved and affect the nature of their involvement. Related to parental involvement and socio-cultural factors, the following comments were made:

Principal 2: $\quad$ Dads are shy to come because it is a female community

Teacher 2:

As a society the mothers like to stay at home and are responsible for children

Teacher 4: Most fathers think it is the role of the mother to come to school. Female to female communication is a cultural norm. I feel more comfortable to talk to the mum. I met the father and I was shy and he 
was not at ease too. It lasted for five minutes. With the mother our meeting would have lasted fifty minutes.

Social Worker 4: $\quad$ The mums find it hard to communicate with male teachers.

Social Worker 3: $\quad$ If ADEC can make a project about parental involvement they can look at the culture of the Emirati society - their customs and traditions and then send more messages about how parents can become more involved.

\section{Implementation of Policy}

ADEC’s Strategic Plan (2009-2018) highlights parent involvement as part of the change agenda that schools need to manage. However, principals' voices confirm confusion related to implementation of policy at the school level:

Principal 3: $\quad$ We need to activate a policy that dictates involvement of parents and this policy should be empowered by ADEC, issued by ADEC and signed by Sheikh Mohammed because people listen to him.

Principal 4: $\quad$ We need to do an agreement with the parents at the beginning of the year that dictates that the parents come to school whenever needed as an obligatory agreement and part of the policy.

Social workers and teachers were unaware of the newly introduced parental involvement policy relevant to home-school relationships:

Social Worker 4: $\quad$ The school encourages the parents to participate but there are no policies.

Teacher 1: $\quad$ The school does not have a policy to encourage or motivate parent involvement.

Teacher 6: $\quad$ No real policies and procedures that I know of exist in the school but parents come and go at the break time from 10.30 -11 am.

\section{Budgeting Restrictions}

Principals note that school-based managerial constraints faced include limited budgets to sponsor workshops and create better communication tools to improve home-school relationships.

Principal 4: $\quad$ We need money to spend on encouraging parents to participate and organizing specialized people to run workshops, help understaffing and breakdowns in communication.

Principal 6: $\quad$ We need a budget to spend on organizing workshops and inviting specialized people to run them.

Principal 7: $\quad$ We need more administrative staff. We need to allocate a person who is in charge of the parents' communication channel. We need some training for teachers to train them on how to communicate with parents. We need a special budget to spend on encouraging parents to 
take part and to organize more activities paying for specialized people to conduct workshops on issues needed such as communication and management. We need special budget for parental involvement money to open continuing education classes for illiterate mums.

\section{Misconceptions of Roles and Responsibilities}

Initiating, managing and determining the nature and type of home-school relationships are factors open to debate as they result in misconceptions of roles and responsibilities and lead to misunderstandings and apportioning of blame and criticism. Principals, social workers and teachers claim that it is the parents' responsibility to be involved. Principals, social workers, teachers and parents talk about the apathy and failure of some parents to get involved. They note this negatively impacts the management of homeschool relationships.

Principal 3: $\quad$ It is the responsibility of parents to be involved. They don't feel the responsibility

Social Worker 1: $\quad$ They should contact the school and know about the daily things all the time. The parents should be close and have a connection. Like a close relation they should know everything.

Social Worker 6: $\quad$ It is very important if they (parents) cooperate with us as we can Improve performance and achievement. The involvement means helping me in my work. I need their support and when they are not involved, I fail in my job and get disappointed. When I organize meetings very few respond and come.

Teacher 2: $\quad$ Some parents do nothing. They think it is the school's job and the school has to do everything for their students. About 30\% think like this. They make a big noise. They call the school and complain about the teacher - "You make my child cry all day. I'm having a job and I'm tired". These parents think that it is not important to talk to the teacher. They stick to traditional ways that talking to the teacher is a wasted time.

Teacher 2: $\quad$ Some parents don't come unless called.

Teacher 3: $\quad$ Parents are not aware of the importance of following up their children at home.

Teacher 4: $\quad$ They need to attend meetings and follow up at home. They need to ask about their children. Through involvement parents can know what difficulties teachers face. If they show initiative and willingness to communicate this will improve the communication channel.

Parent 5: Some parents are very involved but others don't care.

While some parents confirm they help their child "at home in assignments and homework" (Parents 6) and help the school "through helping the teachers" (Parents 7), the common view held is that children's education and welfare are the responsibility of the 
school. Misconceptions of roles and responsibilities lead to apportioning blame and debate as to who is responsible for getting parents involved and managing their involvement in schools. Students noted, "I think the teachers should call our parents more frequently and our parents should try and attend more meetings with our teachers” (Students 3).

\section{Factors Impinging Communication}

Although parents claim that home to school and school to home communication enhances home-school relationships with, "really nice links between us" (Parents 1) and "the school sends us surveys and questionnaires to explore new ways to involve us” (Parents 2), data from this study indicates that the communication flow of information is reduced by shortcomings that have failed to be addressed by systems, structures and processes:

Students 3: $\quad$ In Grade 3 parents attend the class to check on students' behaviour but this does not happen in Grade 5.

Parent 4: $\quad$ The school calls only if there is a problem...rarely they send us letters about our kid's bad behaviour.

Parents 5: $\quad$ We want to be informed regularly but this is not happening.

Parents 4: The Science teacher was absent for 2 months and we were not informed...the school calls only if there is a problem...rarely they send us letters about our kid's bad behaviour.

Parents 7: Weekly handouts sent home are "not in all grades or subjects...some parents receive SMS but not everybody.

Although school social workers coordinate home-school relationships and facilitate opportunities for dialogue, they may not be able to satisfy parents and teachers communication difficulties:

Teacher 7: $\quad$ The social worker calls the parents and communicates with parents but sometimes the parents need information so they knock at the teacher's door while the lesson is going on. This disrupts the lesson.

Timetable issues and heavy teaching workloads leave teachers with little time to communicate with parents or provide them with the support needed to help their children:

Teacher 1: $\quad$ I need to correct students work in break time. I don't have enough time so I call them at the end of the day.

Although structures such as the 'Mothers' Council offer parents a platform to voice an opinion on aspects of schooling and facilitate the organization of social events, workshops and talks, parents note that having decision making input on academic achievement is not on 
the agenda and claims of improving student learning through council work could not be justified.

ADEC's inability to update parents and school authorities regularly on the nature of the reforms place both parties at a disadvantage, "Only sometimes we receive messages from ADEC as far as external exams, registration for programs are concerned” (Parents 7).

School and parent participants both note that parent apathy and failure to get involved negatively impacts home-school relationships. Parent apathy is blamed on claims that "they (parents) can't do it” (Teacher 7). The ramifications of this in practice produce a sense of disillusionment:

Teacher 1: $\quad$ The social worker asked me to prepare a model lesson for the mothers of weak students. I prepared everything but nobody came. A big percentage of parents haven't come to school.

Parents 3: $\quad$ about $30 \%$ think like this.

Parents 4: $\quad$ Non-involved parents make a big noise...call the school and complain that the school can't tell us what is going on.

Students 6: $\quad$ There are some children whose parents are not involved. We feel they are lost.

The Language barrier limits the flow of communication between the EMT teachers and parents. Teachers note that very little assistance is available by way of translators:

Principal 6: $\quad$ Mothers who don't speak English find it hard to communicate with EMT teachers.

Teacher 2: $\quad$ Sometimes when mums are approached they say we don't speak English so how do you expect us to teach our children at home.

Teacher 4: $\quad$ We are teaching in English so we need parents to help. If parents can't understand English they can't help their child.

Teacher 5: $\quad$ Sometimes it is problematic between the EMTs and parents in terms of language and the school needs to provide a translator. In this school we have EMT teachers for Science, Math and English and parents need translation. One person is not always enough. Sometimes communication might be problematic between teachers and the parents. We have to provide another translator. There are gaps between the PPP providers and the parents in terms of language.

Students 7: $\quad I$ wish they would know English so they can help us in Math, Science and English. 


\section{Managerial Adjustments to Enhance Home-school Relationships}

Owing to the changes in the family structure, challenges in the management of home-school relationships have been encountered and yet adjustments to systems, structures and processes have not been fully attended by school authorities. These challenges are presented according to: work commitments, family dissolution, transport difficulties and parent education:

Work commitments:

Principal 5: $\quad$ Most mums don't take part because of work commitments and they can't leave work during the day. Also dads can't come because they can't leave from work. It affects the students negatively if they don't get involved.

Social Worker 2: $\quad$ Being working mums maybe they can't leave their work to check on their children

Teacher 2: $\quad$ Factors that limit parents - the main one is work. Working parents can't come but call. Face to face is much better.

Teacher 4: $\quad$ Time is the factor. Some parents are working and have no time. Some parents have small children and so can't come.

Teacher 5: $\quad$ Working mums can't leave work to take part in the activities. Around $40 \%$ can't be involved because they are working.

Students 2: $\quad$ Busy mums don't come to school.

Parents 2:

Sometimes because I am a working mum it hinders me and teachers don't give their numbers to anyone so working mums can't communicate.

Parents 3: $\quad$ One parent has seven children so that is very difficult.

Family dissolution:

Principal 2: $\quad$ Usually mums of weaker students are mums who suffer from divorce.

Teacher 2: $\quad$ Some mums are really shy to show up. Mothers who are divorced or separated feel shy to come.

Teacher 4: $\quad$ Separation and family problems limit parents' involvement. Out of 37 students 3 are products of broken families.

Transport difficulties:

Principal 6: $\quad$ Transportation is also a problem. Mums have family commitments and transportation problems. She depends on the husband to drive her to school.

Social Worker 4: $\quad$ Mums don't have transportation and husbands don't allow them to catch taxis.

Teacher 4: $\quad$ Some parents do not come to school. They live far away. I have 80 students and only 20 parents come on good days

Low levels of parent education: 
Principal 3: $\quad$ Sometimes uneducated parents with low levels of education can't help their kids especially with the introduction of the new curriculum and English being the medium of instruction.

Principal 4: $\quad$ Sixty percent of the mums don't write and read our communication letters.

Teacher 4: $\quad$ Those who are educated communicate and get involved. They care about their child. Some parents don't know how to use the computer so email is difficult. Sometimes both mums and dads are uneducated and can't help.

\section{Discussion}

The school is part of the community and home-school relationships are considered beneficial because they: enhance student learning and emotional/psychological well being; increase parents' knowledge and understanding of the new curriculum and pedagogical changes brought about by the New School Model; increase parental knowledge and understanding of their children's academic and behavioural needs; develop among school staff an understanding of home circumstances that effect the child; and promote a sense of community.

While acknowledging the aforementioned benefits, findings from this study also highlight the problems and issues schools face in the management of home-school relationships. The implementation of the new curriculum and pedagogies, as part of the school reforms, creates challenges for stakeholders. This is escalated in complexity due to new pedagogies communicated to parents in an ad hoc manner and the limited English proficiency of parents. A language barrier on the level of comprehending the curriculum and communicating with EMTs forms part of the situated nature of problems experienced in context that contributes to a series of demands in managing home-school relationships. These include, for example, the need for organizational structures, systems and processes that can manage the absorption of the new reforms.

The literature states that change management cannot be undertaken in a vacuum (Hargreaves \& Fink, 2006; Dantley, 2005; Pristine \& Nelson, 2005; Lam \& Punch, 2001); schools are part of complex systems influenced by macro and micro educational decisions. The educational landscape of Abu Dhabi indicates that this is a time of rapid educational reform and change. Establishing home-school relationships in such a context of reform and change has been endorsed by the data as a challenging process. For example, the introduction 
of English as a medium of instruction for Math and Science, changes in the curriculum, assessments and pedagogy and newly appointed English medium teachers from the West contribute to the challenges schools face. The findings indicate that logistics and mechanisms of communication need to be strengthened by the administration to bridge the gap between home and school. Managerial decisions are needed in the design of systems, structures, and processes for better adjustment to the New School Model.

The significance and value of promoting positive home-school relationships, albeit traceable to ADEC's Strategic Plan and Policy 4.4 (ADEC, 2010a), needs further detailing of roles and responsibilities of parents and schools in the management of home-school relationships. Data from this study indicates that these roles and responsibilities need to be functionalized by both the school administration and ADEC; at this point in time, roles and responsibilities are not facilitated through any clearly defined means of systems, structures and processes. What was clear is that the roles and responsibilities stated in ADEC's Strategic Plan align with both Epstein's (2001) six dimensions of home-school relationships and Obeidat and Al-Hassan's (2009) categories of parental involvement. However, in the context of Abu Dhabi PPP schools, the absence of the means to facilitate and implement these dimensions at the home/school level was missing.

The findings suggest that school authorities need to make organizational adjustments to suit parental needs. School to home and home to school systems, structures and processes are in fluctuation and have contributed to the constraints and confusions felt by all the stakeholders. For example, communication systems, structures and processes are not fully established and are evolving in response to reform initiatives and socio-cultural demands in an ad hoc manner. It was noted by the stakeholders that a lack of pathways to implement home-school relationships and interruptions in communication has negatively impacted the management of home-school relationships at all levels. Stakeholders noted that some issues to resolve communication difficulties are within the scope of schools and this would involve on-going support, knowledge building and understanding of the community's needs. Findings also revealed the need for ADEC to initiate their own systems, structures and processes to support and maintain open communication among all stakeholders. The fundamental gap in communicating information on the reforms to schools, community and ADEC needs bridging. ADEC's input to schools by way of budgetary and communication support will 
support the development of systems, structures and processes in successful management of home-school relationships.

Although all stakeholders considered the process of education and teaching and learning to be two channelled, it was noticeable that a polarization among stakeholder groups exists as to their perceived roles and responsibilities. Principals, social workers and teachers considered it the parents' responsibility to get involved and support their attempts to enhance student learning. Parents felt it was mainly the schools' responsibility to promote homeschool relationships. Principals did not involve parents in strategic academic decision making. Their focus was on home-based involvement and follow up on learning and social and emotional behaviour. Parents, however, indicated their willingness to become more involved in the academic side of school life in addition to participating in the "Mothers' Council” and contributing towards school run social and cultural events.

Although the literature review conveyed the existence of parental involvement Policy 4.4 (ADEC, 2010a), the findings showed that this policy was not communicated to stakeholders. The findings reflected a level of ambiguity and a lack of transparency between stakeholders and ADEC on Policy 4.4 details. Stakeholders suggested that pathways to implement policy were missing and unidentified by ADEC. This has hampered home-school communication channels and polarized perceptions of stakeholders' roles and responsibilities. In the management of home-school relationships, this polarization needs to be addressed on both macro and micro levels.

Data from this study confirms that effective management of home-school relationships necessitates connectedness among all stakeholders at the parent/school/ADEC interface and across all levels of the school organization. In this respect, stronger ADEC, school, parent links that enhance and sustain home-school relationships are needed through systems, structures and processes that promote meaningful communication. Based on the findings, improvements would mean school restructuring in line with the demands of current school changes and reforms. This would necessitate:

- Working towards developing a structural model for implementing ADEC's vision of parental involvement in schools as stated Policy 4.4 
- Developing robust systems, structures and processes that manage tensions of context in cohesive, comprehensive ways

- Initiating professional development for parents with a view to building their knowledge base about pedagogical and curriculum changes

- Ensuring connectedness among stakeholders through systems, structures and processes that reflect the community’s culture and a focus on student learning.

\section{Recommendations}

The following section presents recommendations for ADEC, schools and parents.

\section{Implications for ADEC}

ADEC's policy on schools initiating and managing home-school relationships presents major challenges given the complexities of context. Schools and parents need to feel reassured that parental involvement is not an isolated venture and that support from ADEC can be relied on to contribute to successful management of home-school relationships. ADEC needs to be more open and cognisant of the suggestions school stakeholders make as to what works reflective of context. Budgetary allocations and a situated, connected response to highly complex cultural issues will sustain and strengthen schools' capacities to make structural changes in the management of home-school relationships that is unique to setting.

\section{Implications for School Staff}

It is essential that school staff continue to adopt a critical stance in reforming their organisations and improving their existing systems, structures and processes. A deeper, critical analysis of socio-cultural factors will bridge the gap between the rhetoric that accompanies policy and what happens in practice. It will foster the management of homeschool relationships in context. The constraints that are socio-cultural need to be addressed by school stakeholders collectively. The voices of school stakeholders offer ground level support for school restructuring and successful management of home-school relationships.

\section{Implications for Parents}

If enhancing home-school relationships is desirous, then the preservation and honouring of the true meaning of partnership is required. Parents must critically assess and 
voice issues that concern them. Without this recognition of voice, existing practices are liable to continue unchallenged and the true worth of home-school relationships may fail to materialise.

\section{Conclusion}

This study has explored the managerial aspects of home-school relationships in the context of Abu Dhabi. It has identified the loops within the communication systems, structures and processes of schools in terms of the newly introduced school reforms and policy. This qualitative, exploratory study has produced interesting findings in terms of current trends and patterns associated with home-school relationships in Abu Dhabi. The findings conclude that a gap has been created between the policy-rhetoric of ADEC in promoting home-school relationships (ADEC, 2010a) and the reality of its implementation in practice.

Management of home-school relationships must be considered a process in progression. The findings are valuable in that they propose amendments to policy implementation in line with the socio-cultural context. Systems, structures, and processes are managerial aspects that assist with promoting home-school relationships. School systems, structures and processes need to continue to evolve in response to individual, collective and systemic need reflective of context. Alignment to proposed recommendations will promote flexible, adaptable and sustainable infrastructures that meet the needs of all school stakeholders.

Overall, the suggestion made calls for effective dialoguing among all stakeholders to develop a framework that effectively manages home-school relationships in context. Data, collected, collated, analysed and interpreted provides a much needed information base from which to pursue further research in this area. Here, a longitudinal study over a period of one or two years in a range of schools is proposed as it will capture the evolving nature of systems, structures and processes in support of home-school relationships. 


\section{REFERENCES}

Abu Dhabi Education Council (2008). Together, ADEC Newsletter, 1, 1. Abu Dhabi: Abu Dhabi Education Council.

Abu Dhabi Education Council (2009). Abu Dhabi Education Council Strategic Plan for P-12 Education (2009-2018) Abu Dhabi: Abu Dhabi Education Council.

Abu Dhabi Education Council (2010a). New School Model Manual. Abu Dhabi: Abu Dhabi Education Council.

Abu Dhabi Education Council. (2010b). Abu Dhabi Education Policy Agenda. Abu Dhabi: Abu Dhabi Education Council.

Dantley, P. (2005). Moral Leadership: Shifting the Management Paradigm. In F. W. English (Ed.), The Sage Handbook of Educational Leadership. Advances in Theory Research, and Practice (pp. 34-47). Thousand Oaks: Sage.

Davies, D. (1999). Education and the Arab World Partnership: A Theme for Education and Communities in the Twenty- First Century (51-88).UAE: The Emirates Centre for Strategic Studies and Research.

Denzin, N. K., \& Lincoln, Y. S. (2003). Strategies of Qualitative Inquiry (2 ${ }^{\text {nd }}$ Ed.). Thousand Oaks: Sage.

Epstein, J. (2001). School, family and community partnerships: Preparing educators and improving schools. Boulder, Colorado: Westview Press.

Fan, X., \& Chan, M. (2001). Parental involvement and students' academic achievement: A metaanalysis. Educational Psychology Review, 13(1), 1-22.

Fullan, M. G. (1993). The complexity of the change process In Change forces: Probing the depth of educational reform. U.S.A: Falmer Press.

Hargreaves, A. \& Fink, D. (2006). The Ripple Effect. Educational leadership, 63(8), 3-21.

Harris, A., \& Goodall, J. (2008). Do parents know they matter? Engaging all parents in learning. Educational Research, 50(3), 277-289.

Hill, N. \& Tyson, D. (2009). Parental involvement in middle school: A meta-analytic assessment of strategies that promote achievement. Developmental Psychology, 45(3), 740-763.

Honig, M., \& Hatch, T. (2004). Crafting Coherence: How Schools Strategically Manage Multiple, External Demands. Educational Researcher, 33(8), 16-30.

Hoover-Dempsey, K. V.; Battiato, A. C.; Walker, J. M. T.; Reed, R. P.; DeJong, M. \& Jones, K. P.(2001). Parental Involvement in Homework. Education Psychologist, 36(3), 195-209.

Hu, G. (2002). Potential cultural resistance to pedagogical imports: The case of communicative Language teaching in China. Language, Culture and Curriculum, 15(2), 93-105.

Kanaan, P. (2008). Education Reforms on the Fast Track. Retrieved April 23, 2009, from http://Khaleejtimes.com.accessed 7/1/. 
Khan, B. (1996). Parental Involvement in Education: Possibilities and limitations. The School Community Journal, 6(1), 57-66.

Khasawneh, O. \& Alsagheer, A. (2007) Family-School Partnership for Enhancing Pupils' Learning: A Proposed Model, Journal of Faculty of Education UAEU, 24, 47-71.

Lam, Y. L. J., \& Punch, K, F. (2001). External Environment and School Organisational Learning: Conceptualising the Empirically Neglected. Leadership and Learning, 29(3), 28-39.

Merriam, S. (1998). Qualitative research and case study applications in education. San Francisco: Jossey-Bass Inc.

Morgan, D. (1997). Qualitative Research Methods. U.S.A.: Sage

Nunan, D. (2003). The impact of English as a global language on educational policies and practices in the Asia-Pacific region. TESOL Quarterly, 37(4), 589 - 613.

Obeidat, O. \& Al Hassan, M. (2009). School- Parent- Community Partnerships: The experience of teachers who received the Queen Rania award for excellence in education in Hashemite Kingdom of Jordan. School Community Journal, 19 (1), 119-136.

Patton, M. Q. (1990). Qualitative evaluation and research methods. (2 ${ }^{\text {nd }}$ Ed.) Newbury Park: Sage.

Pristine, N. A., \& Nelson, B. S. (2005). How can educational leaders support and promote teaching and learning? New conceptions of learning and leading Schools. A New Agenda for Research in Educational Leadership, (46-61). New York: Teachers College Press.

Rae. K. (2005). More busy-work for schools. New Zealand Journal of Educational Leadership. 20(1), 95-97.

Safran, D. (1997). The Psychology and Politics of Parent Involvement: Abu Dhabi. The Emirates Center for Strategic Studies and Research.

Wylie, C. (1999). Ten Years On: How Schools View Educational Reform. Wellington: New Zealand Council for Educational Research.

http://www.ameinfo.com/242007.html. Abu Dhabi Education Council press release. ADEC launches New School Model. Retrieved May 29, 2012.

http:WWW.adec.ac/ ADECNSM STRATEGY. ADEC 10 Years Strategic Plan. Retrieved May 29, 2012. 